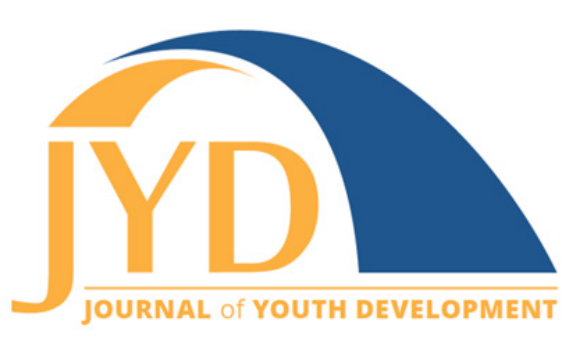

http://jyd. pitt. edu/ | Vol. 12 Issue 4 DOI 10.5195/jyd. 2017.579 | ISSN 2325-4017 (online)

\title{
Strategies to Scale Up Social Programs: Pathways, Partnerships and Fidelity
}

\author{
Priscilla Sanchez \\ YMCA of the USA \\ priscilla.sanchez@ymca.net
}

\begin{abstract}
Strategies to Scale Up Social Programs: Pathways, Partnerships and Fidelity (Larson, Dearing, \& Backer, 2017) summarizes a comparative case study of 45 social programs that scaled up. Three pathways, various partnerships, and fidelity considerations are discussed. This resource, commissioned by The Wallace Foundation, will be helpful to youth development organization leaders desiring to scale up. Youth development practitioners will benefit from the discussion on fidelity considerations in implementation.
\end{abstract}

As the field of youth development continues to grow and programs are refined, leaders at youth development organizations may feel a responsibility to expand interventions to more individuals in need of services. For example, YMCA of the USA heeded the call to address the achievement gap (http://www.ymca.net/achievement-gap) back in 2011, with seven sites in an after-school program, and most recently in more than 260 sites across the nation. Expanding services must be planned methodically, with structures and resources in place to successfully reach more youth. Youth development organization leaders considering or planning to expand should read a report published in September 2017 titled Strategies to Scale Up Social Programs: Pathways, Partnerships and Fidelity (Larson, Dearing, \& Backer, 2017).

The report contains results of a comparative case study of 45 social programs that were all brought to scale. To identify programs to include in the study, evaluators searched for and reviewed documents from organizations and obtained recommendations from expert informants. Programs were selected if they focused on education, youth development or health and if they effectively scaled up; documents were reviewed for evidence of program scaling,

(cc) EY New articles in this journal are licensed under a Creative Commons Attribution 4.0 License. This journal is published by the University Library System, University of Pittsburgh and is cosponsored by the University of Pittsburgh Press. The Journal of Youth Development is the official peer-reviewed publication of the National Association of Extension 4-H Agents and the National AfterSchool Association. 


\section{Strategies to Scale Up Social Programs}

such as number of sites and/or beneficiaries served and indication of at least one partner. Once the 45 programs were selected, 100 leaders at 44 of the social programs were interviewed to gather supplementary information to what was included in the documents. Finally, four programs were selected for additional in-person and on-site interviews so that the evaluators could gain a deeper understanding of their scaling efforts and to serve as illustrations for the pathways.

The report identifies 3 components in scaling social programs:

Pathways - Although there are different paths to scaling, the report highlights three that were common among the 45 social programs:

- Branching: A lead organization offers a program to new sites or to new target groups (Mulgan, Ali, Halkett \& Sanders, 2007; Dees, Anderson \& Wei-Skillern, 2004; Kalafatas, 2006)

- Affiliate: An implementing organization buys the rights, often through a contract, from a lead organization to offer the social program (Gabriel, 2014; Mulgan, Ali, Halkett \& Sanders, 2007)

- Distribution network: A lead organization "piggybacks" on another organization's network and structures (Gabriel, 2014)

Partnerships - Social programs in the study did not scale up without assistance; the following were the most common types of partners:

- Lead partner: leads scaling efforts

- Distribution partner: provides connection to local implementers

- Implementing partner: offers direct services

- Supporting partner: gives funding and/or expertise

Fidelity - Scaling up might require making one or two of these types of changes to the program intervention such as:

- Reinvention: Changes made to the program prior to scale-up by the lead partner. The report identifies three types of partner involvement in reinvention:

- Integrative reinvention: The lead partner shares control in reinvention decisions with a partner organization which leads to changes in structure or practices of the partner organization; roles may blur. 
Strategies to Scale Up Social Programs

- Interactive reinvention: The lead partner seeks program modification information and is the sole decision maker, or a partner may also have a say; organization identities remain separate.

- Contractual reinvention: The lead partner manages reinvention through a contract with a partner; organization relationships are low in interdependence.

- Adaptation: Changes made to the program for implementation purposes by implementers. The resource classifies four types of adaptation decisions:

- Prescriptive fidelity: Adaptation is discouraged, and implementation is monitored.

- Expectant fidelity: Adaptation is discouraged, and implementation is not monitored.

- Responsive adaptation: Adaptation is encouraged as the lead partner responds to feedback, and implementation is monitored.

- Independent adaptation: Adaptation is encouraged, and implementation is not monitored.

The sections on fidelity and implementation define types of program adaptations and how they fit into the larger picture of scaling up, which may be useful to practitioners. However, given that practitioners are not the primary audience, there is an absence of in-depth information on processes implemented by practitioners at the 45 social programs to make successful adaptation. Moreover, it would have been helpful to learn how practitioners' common concerns about scaling and implementation were addressed, how shifts in program and evaluation were successfully managed on the front lines, and what resources implementers found helpful. This type of information would also benefit leaders in organizations by providing insight on the type of support, training, and resources implementers found most effective. Since practitioners have the most contact with program participants and communities served, it would have been useful to understand what kinds of feedback strategies they used when sharing implementation and fidelity observations with leadership in order to provide context to adaptation monitoring. Given the magnitude of the study, it is understandable that topics delving into practitioner support were mainly out of scope for the project.

This 90-page free report, commissioned by The Wallace Foundation, is an excellent resource for individuals in leadership roles who make decisions about scaling and forming partnerships. There is an executive summary to provide a general overview for individuals who want to quickly understand the study and have the option to dive deeper into subsequent chapters. It fully describes three types of pathways in separate chapters while tying in partnership roles and fidelity considerations. Conducting a comparative case study of 45 programs is no small feat, 
and the authors carefully integrate information from the programs to concretize how scaling dynamics look in practice. The authors include scaling research findings as well as a list of funders who support organizations' programs and their scale-up efforts. This type of resource is needed as youth development organizations yield to the responsibility of reaching individuals in need of social services.

The report is available at: http://www.wallacefoundation.org/knowledgecenter/Documents/Strategies-to-Scale-Up-Social-Programs.pdf

\section{References}

Dees, G., Anderson, B., \& Wei-Skillern, J. (2004, Spring). Scaling social impact. Stanford Social Innovation Review, 1(4), 24-32.

Gabriel, M. (2014). Making it big: Strategies for scaling social innovations. London, UK: Nesta.

Kalafatas, J. (2006). Approaches to scaling social impact. [PowerPoint slides]. Retrieved from: https://centers.fuqua.duke.edu/case/ knowledge_items/approaches-to-scaling-social-impact/

Larson, R. S, Dearing, J. W., \& Backer, T. E. (2017). Strategies to Scale Up Social Programs: Pathways, Partnerships and Fidelity. Retrieved from The Wallace Foundation website: http://www.wallacefoundation.org/knowledge-center/Documents/Strategies-to-Scale-Up-SocialPrograms.pdf

Mulgan, G., Ali, R., Halkett, R. \& Sanders, B. (2007). In and Out of Sync. London: NESTA. Available at http://www.nesta.org.uk/publications/and-out-sync 